\title{
PENGATURAN DIRI DAN PRESTASI AKADEMIK PESERTA DIDIK SMA PADA MATERI USAHA DAN ENERGI
}

\author{
Syifa Khusnul Fatimah, Ridwan Efendi, Winny Liliawati. \\ Departemen Pendidikan Fisika Fakultas Pendidikan Matematika dan Ilmu Pengetahuan Alam, \\ Universitas Pendidikan Indonesia \\ Email: syifakhusnulfatimah@student.upi.edu
}

Diterima: 2 Agustus 2020 Disetujui: 31 Agustus 2020

\begin{abstract}
Abstrak
Pengaturan diri adalah sikap yang dilakukan oleh peserta didik dalam merencanakan strategi pembelajaran untuk memperoleh prestasi akademik yang baik. Pengaturan diri peserta didik dapat diketahui salah satunya melalui tugas pengaturan diri dimana setiap peserta didik menentukan tugas-tugas pembelajaran yang sesuai dengan kebutuhan belajarnya. Untuk menyelidiki pengaturan diri peserta didik dilakukan penelitian dengan metode mixed methods pada 31 peserta didik kelas X MIPA di salah satu SMA di Kota Bandung. Penelitian dilakukan dengan, 1) Memberikan pembelajaran mengenai usaha dan energi; 2) Memberikan tes kemampuan kognitif kepada peserta didik sebelum intervensi; 3) Peserta didik melakukan penilaian diri untuk mendeteksi kesalahan pada hasil tes dengan bantuan rubrik penilaian; 4) Peserta didik mengerjakan tugas pengaturan diri; 5) Melakukan tes kemampuan kognitif setelah intervensi. Pengaturan diri peserta didik didapatkan dari hasil pemilihan tugas pengaturan diri. Hasil data kuantitatif menunjukkan bahwa pemilihan tugas pengaturan diri belum didasarkan pada hasil penilaian diri. Hasil data kualitatif hanya 32,26\% peserta didik yang menggunakan hasil penilaian diri sebagai dasar pemilihan tugas pengaturan diri, dan sebanyak $61,29 \%$ peserta didik memilih tugas pengaturan diri karena merasa harus memperbaiki proses penyelesaian soal. Hal tersebut dikarenakan peserta didik masih belum cukup baik ketika melakukan penilaian diri dan belum memahami sepenuhnya rubrik penilaian yang diberikan.
\end{abstract}

Kata Kunci: : Pengaturan Diri, Tugas Pengaturan Diri, Penilaian Diri.

\begin{abstract}
Self regulation is the attitude taken by students in learning strategies to obtain better academic achievement. Self regulation can be known as one of them through self regulation tasks where each student can determine learning tasks in accordance with their learning needs. To investigate students' self regulation a research was carried out using the mixed method was conducted on 31 students of grade 10 from a high school in Bandung. The study was conducted by, 1) Give lessons about work and energy; 2) Providing cognitive ability test to students before intervention; 3) Conduct self assessment to detect errors in test results with the help of assessment rubrics; 4) Carry out self regulatory task; 5) Conduct cognitive ability test after intervention. Self regulation of students is obtained from the results of
\end{abstract}


Fatimah., Efendi., Liliawati - Keakuratan Pemilihan Tugas ...

self regulation tasks. The results of quantitative data indicate that the selection of self regulation tasks has not been based on the results of self assessment. The results of qualitative data are only 32,26\% of students who use the results of self assessment as a basic for the selection of self regulation task, and as many as 61,29\% of students choose self regulation tasks because they feel they have to improve the process of problem solving. That is because students are still not good enough when conducting error detection activities and don't understand the assessment scripts.

Keywords: Self Regulation, Self Regulation Task, Self Assessment.

\section{PENDAHULUAN}

Self-regulation (pengaturan diri) merupakan suatu sikap yang dilakukan oleh peserta didik dalam merencanakan strategi pembelajaran untuk mencapai tujuan pembelajaran dan memperoleh prestasi akademik yang baik (Supriyanto, 2017). Pengaturan diri terdiri dari dua elemen penting; pertama, pengembangan pengetahuan tentang domain subjek dan diri sendiri sebagai pelajar; kedua, pengaturan pembelajaran secara mandiri, yang melibatkan perencanaan, pemantauan, serta perbaikan terhadap pembelajaran mandiri dan kegiatan kognitif seseorang (Zimmerman, 2001). Pengaturan diri dapat ditinjau dari beberapa aspek yaitu, aspek kognitif (kemampuan pengaturan diri), yang dapat diukur melalui instrumen tes yang diberikan kepada peserta didik dan indikator tiap butir soal disesuaikan dengan materi yang akan diujikan; aspek motivasi dan metakognisi, aspek tersebut diukur menggunakan skala sikap dan lembar observasi kinerja peserta didik (Sari, 2014).

Peserta didik secara mandiri memantau pembelajaran dan pemahaman mereka untuk mengidentifikasi kemungkinan hambatan yang dapat terjadi melalui kegiatan penilaian diri dan cara mengatasinya. Penilaian diri dilakukan sepanjang siklus pengaturan diri yaitu peserta didik menilai manajemen waktunya, penggunaan strategi pembelajaran, regulasi emosional, kemajuan menuju penyelesaian tugas, dan aspek-aspek lain dari pembelajaran (Tapia \& Panadero, 2010). Penilaian diri merupakan komponen penting dalam pengaturan diri yang dapat mendorong pembelajaran mandiri dan 
Fatimah., Efendi., Liliawati - Keakuratan Pemilihan Tugas ...

meningkatkan keberhasilan akademik (Lin-Siegler, Shaenfield, \& Elder. (2015); Panadero, Jonsson, \& Botella. (2017)). Penilaian diri mempengaruhi tiga fase pengaturan diri yaitu, pada fase pemikiran kedepan memungkinkan peserta didik untuk menetapkan tujuan berdasarkan penilaian; pada fase kinerja untuk merangsang pemantauan kemajuan; dan pada fase refleksi diri untuk mempromosikan hasil penilaian berdasarkan kriteria yang telah ditetapkan. Oleh karena itu, pengembangan kemampuan penilaian diri sangat penting untuk mengembangkan kemampuan pengaturan diri peserta didik.

Ketika melakukan penilaian diri, peserta didik menilai dengan bantuan rubrik penilaian yang telah dibuat oleh guru sebelumnya. Rubrik penilaian terdiri dari tiga karakteristik yaitu, daftar kriteria untuk menilai tujuan penting dari tugas, skala penilaian untuk setiap tingkat pencapaian yang berbeda, dan deskripsi untuk setiap tingkat pencapaian kualitatif (Panadero, Tapia, \& Huertas, 2012). Rubrik penilaian terdiri dari dua jenis yaitu analitis, dimana peserta didik menilai sendiri kinerja mereka pada setiap kriteria kemudian menjumlahkan skor pada setiap kriteria menjadi skor total yang didapatkan peserta didik; dan holistik, dimana kriteria yang digunakan lebih umum dan penilaiannya lebih global (Tapia \& Panadero, 2010). Standar jawaban yang tepat atau standar penilaian yang tercantum dalam rubrik penilaian untuk setiap langkah pemecahan masalah dapat meningkatkan kemampuan penilaian diri dan kinerja peserta didik pada jenis permasalahan yang sama. Dari hasil penelitian yang dilakukan oleh Tapia \& Panadero (2010) menyatakan bahwa menggunakan rubrik penilaian dapat meningkatkan pengaturan diri dan pembelajaran. Pada hasil penelitian yang dilakukan oleh Zamora, Suarez, \& Ardura (2016), peserta didik kesulitan dalam penilaian diri mereka bahkan ketika menggunakan rubrik penilaian sehingga mereka kesulitan dalam menentukan tugas selanjutnya yang didasarkan pada kesalahan mereka.

Pelatihan kemampuan pengaturan diri pada peserta didik dapat berupa 
Fatimah., Efendi., Liliawati - Keakuratan Pemilihan Tugas ...

tugas individu mengenai materi yang sedang diajarkan yang ditentukan sendiri oleh peserta didik sesuai dengan kebutuhan belajarnya dengan tujuan untuk memperbaiki dan meningkatkan pembelajaran.

Memberi peserta didik kesempatan untuk mengontrol tugas-tugas pembelajaran yang mereka kerjakan yang dapat meningkatkan keterampilan pembelajaran mandiri mereka (Kostons, Van Gog, \& Paas, 2012). Pemilihan tugas dipengaruhi oleh hasil penilaian diri, jika penilaian diri tidak akurat maka berdampak negatif pada pemilihan tugas selanjutnya. Ketika pemilihan tugas tidak akurat atau tidak sesuai dengan tingkat kemampuan peserta didik sebelumnya (pengetahuan dan keterampilan), peserta didik akan mengerjakan tugas yang tidak sesuai dengan kebutuhan belajar mereka. Pada hasil penelitian yang dilakukan oleh Zhou (2013), menunjukan bahwa peserta didik yang memiliki kemampuan baik dapat menghubungkan aktivitas pengaturan diri dengan tujuan yang mereka tentukan. Dalam praktek dilapangan, peserta didik cenderung akan memilih tugas yang mereka kuasai saja yang akhirnya tidak sesuai dengan kebutuhan belajar (Kostons, Van Gog, \& Paas, 2012; Zamora, Suarez, \& Ardura, 2016) serta peserta didik dapat melakukan pemilihan tugas pengaturan diri tetapi tidak mendasarkan keputusan pilihan tugas pada hasil penilaian diri (Nugteren, dkk. 2018).

Oleh karena itu, untuk mengetahui kemampuan pengaturan diri peserta didik pada materi usaha dan energi serta dampaknya terhadap prestasi akademik dilakukan penelitian yang meminta peserta didik untuk memilih secara mandiri tugas pembelajaran selanjutnya dan diharapkan dapat membantu prestasi akademik peserta didik.

\section{METODE}

Penelitian dilakukan menggunakan metode mixed method pada 31 peserta didik yang terdiri dari 19 orang perempuan dan 12 orang lakilaki, kelas X MIPA di salah satu SMA di Kota Bandung secara daring menggunakan aplikasi google classroom, grup whatsapp, dan google formulir. Pembelajaran materi 
Fatimah., Efendi., Liliawati - Keakuratan Pemilihan Tugas ...

usaha dan energi dibagi menjadi tiga kali pertemuan dengan sub materi usaha, energi, dan hukum kekekalan energi. Setelah pembelajaran dilakukan, proses pengumpulan data penelitian untuk mengetahui kemampuan pengaturan diri peserta didik pada materi usaha dan energi serta dampaknya terhadap prestasi akademik dilakukan menggunakan pendekatan kuantitatif dan kualitatif. Metode pengumpulan data kuantitatif dilakukan dengan memberikan tes kemampuan kognitif tentang materi usaha dan energi berbentuk uraian berjumlah 11 butir soal (preintervention test) dengan waktu 90 menit. Pada setiap butir soal peserta didik melakukan penilaian diri terhadap hasil tes yang dibandingkan dengan rubrik penilaian dengan rentang 0-4. Setelah melakukan penilaian diri, peserta didik memilih tugas pengaturan diri berupa pilihan soal-soal pada tes kemampuan kognitif yang menurut mereka masih terdapat kesalahan yang dikerjakan dan dikumpulkan ketika akan melaksanakan post-intervention test. Untuk mengetahui dampaknya terhadap prestasi akademik peserta didik, dilakukan tes kemampuan kognitif kembali (post-intervention test) yang dilakukan tiga hari setelah pelaksanaan pre-intervention test. Soal pre-intervention dan postintervention test disusun berdasarkan indikator capaian kompetensi yang sama tetapi memiliki stimulus soal (berupa angka dan fenmena fisika) yang berbeda. Data kualitatif diperoleh dengan menggunakan angket respon peserta didik dengan pertanyaan terbuka untuk menemukan faktor ataupun hal-hal yang berkaitan dengan hasil data kuantitatif.

Data kuantitatif yang terkumpul berupa skor hasil penilaian diri, skor tugas pengaturan diri, serta skor aktual pre-intervention dan postintervention test. Skor aktual preintervention dan post-intervention test diolah menggunakan statistik deskriptif dan analisis perbedaan ratarata menggunakan uji Wilcoxon dengan bantuan aplikasi SPSS untuk melihat hasil tes kemampuan kogniti berbeda signifikan. Skor hasil penilaian diri dan skor tugas pengaturan diri tersebut kemudian diolah menggunakan statistik deskriptif dengan bantuan aplikasi 
Fatimah., Efendi., Liliawati - Keakuratan Pemilihan Tugas ...

pengolah data microsoft excel.

Pengaturan diri peserta didik

diketahui melalui keakuratan

pemilihan tugas pengaturan diri yang

didasarkan hasil penilaian diri.

Keakuratan pemilihan tugas

pengaturan diri merupakan persentase

pengerjaan tugas pengaturan diri yang

dibandingkan dengan persentase hasil

penilaian diri peserta didik pada hasil

pre-intervention test. Hal tersebut dapat dikatakan akurat jika persentase antara tugas pengaturan diri dan persentase penilaian diri sama atau hampir sama.

\section{HASIL DAN PEMBAHASAN}

Penilaian diri pada hasil preintervention test, dilakukan dengan cara peserta didik membandingkan hasil jawaban pre-intervention test dengan kriteria jawaban pada rubrik penilaian (Lampiran 1) kemudian diberi skor sesuai dengan kriteria jawaban yang terpenuhi. Tabel 1 menunjukkan hasil penilaian diri, persentase penilaian diri, persentase pemilihan tugas pengaturan diri, serta skor aktual pre-intervention dan postinterventin test.

Tabel 1. Rata-Rata dan Standar Deviasi Skor Pre-intervention dan Postintervention Test, Hasil Penilaian Diri, dan Tugas Pengaturan Diri

\begin{tabular}{lrr}
\hline & Mean & $\begin{array}{r}\text { Standar } \\
\text { Deviasi }\end{array}$ \\
\hline \hline Skor Aktual Pre-intervention Test & 23,45 & 9,05 \\
\hline Skor Aktual Post-intervention Test & 34,00 & 6,31 \\
\hline Penilaian Diri Pre-intervention Test & $28,37 \%$ & 23,29 \\
\hline Tugas Pengaturan Diri & $43,70 \%$ & 26,20 \\
\hline
\end{tabular}

Persentase penilaian diri diperoleh dari skor yang diperoleh merupakan persentase deteksi peserta didik ketika mengerjakan kesalahan pada hasil pre-intervention tugas pengaturan diri, serta skor test peserta didik yang diperoleh dari aktual merupakan skor hasil prejumlah skor maksimal dikurangi intervention dan post-interveention dengan skor hasil penilaian diri test peserta didik.

kemudian dibuat persentase, dan Tugas pengaturan diri bertujuan persentase tugas pengaturan diri agar peserta didik secara mandiri 
Fatimah., Efendi., Liliawati - Keakuratan Pemilihan Tugas ...

dapat menentukan dan memperbaiki strategi belajar yang sesuai dengan kebutuhan mereka sehingga mereka mampu menyelesaikan persoalanpersoalan yang diberikan. Keakuratan pemilihan tugas pengaturan diri secara kuantitatif didapatkan dari persentase pemilihan tugas yang dibandingkan secara statistik deskriptif dengan persentase hasil penilaian diri yang telah dilakukan yang tercantum pada Tabel 1. Tugas pengaturan diri yang dipilih oleh peserta didik seharusnya didasarkan pada hasil penilaian diri yang telah mereka lakukan dengan ciri persentase rata-rata hasil penilaian diri sama dengan persentase rata-rata pemilihan tugas dengan perbedaan yang cukup besar yaitu $15,47 \%$. Pada
Tabel 1, terlihat bahwa peserta didik cenderung lebih banyak memilih tugas pengaturan diri dibandingkan identifikasi kesalahan yang mereka lakukan pada pre-intervention test. Hal tersebut sejalan dengan hasil penelitian yang dilakukan oleh Zamora, Suárez, \& Ardura (2016) yang menunjukkan bahwa persentase pemilihan tugas pengaturan diri lebih besar dibandingkan dengan persentase penilaian diri yang dilakukan oleh peserta didik.

Pada lembar tugas pengaturan diri, peserta didik diberikan kolom alasan pada setiap butir soal yang dipilih untuk dikerjakan kembali. Alasan-alasan yang diberikan oleh peserta didik ditunjukkan pada Tabel 2.

Tabel 2. Alasan Pengerjaan Tugas Pengaturan Diri

\begin{tabular}{lc}
\hline \multicolumn{1}{c}{ Alasan Peserta Didik } & $\begin{array}{c}\text { Persentase } \\
\text { Peserta didik } \\
(\%)\end{array}$ \\
\hline $\begin{array}{l}\text { Melengkapi dan memperbaiki jawaban yang telah dikerjakan, } \\
\text { karena belum sesuai dengan rubrik penilaian / kriteria } \\
\text { jawaban soal }\end{array}$ & 35,71 \\
\hline $\begin{array}{l}\text { Merasa kurang maksimal dan tidak yakin dalam mengerjakan } \\
\text { soal-soal yang diberikan }\end{array}$ & 9,52 \\
\hline Belum memahami soal yang diberikan & 19,05 \\
\hline Untuk melatih kemampuan menyelesaikan soal & 19,05 \\
\hline $\begin{array}{l}\text { Memperbaiki pola belajar agar dapat menyelesaikan berbagai } \\
\text { jenis soal }\end{array}$ & 2,38 \\
\hline
\end{tabular}


Fatimah., Efendi., Liliawati - Keakuratan Pemilihan Tugas ...

\begin{tabular}{lc}
\hline & \\
\hline Alasan Peserta Didik & $\begin{array}{c}\text { Persentase } \\
\text { Peserta didik } \\
(\%)\end{array}$ \\
\hline \hline Melatih ketelitian dalam mengerjakan soal & 11,90 \\
\hline $\begin{array}{l}\text { Ada yang tidak mengerjakan karena sudah sangat yakin } \\
\text { dengan jawaban yang telah dikerjakan }\end{array}$ & 2,38 \\
\hline
\end{tabular}

Sebanyak $2,38 \%$ peserta didik tidak memilih tugas pengaturan diri karena sudah sangat yakin dengan jawaban yang dikerjakan. Sedangkan alasan-alasan yang dikemukakan oleh peserta didik ketika melakukan tugas pengaturan diri sangat beragam mulai dari melengkapi dan memperbaiki jawaban, merasa jawaban kurang maksimal, melatih ketelitian dalam mengerjakan soal, serta memperbaiki pola belajar. Dengan alasan yang dikemukakan oleh peserta didik, disimpulkan sementara bahwa peserta didik cenderung mengerjakan tugas pengaturan diri berdasarkan kemauan dan kebutuhan mereka tanpa menggunakan hasil penilaian diri sebagai acuannya.

Oleh karena itu, setelah peserta didik melakukan post-intervention test diberikan angket respon peserta didik yang bertujuan untuk mengetahui respon peserta didik tentang pelaksanaan penilaian diri dalam aktivitas penilaian diri terhadap pemilihan tugas pengaturan diri diberikan pertanyaan "Berikan pendapat Anda tentang pelaksanaan penilaian diri sendiri terhadap pemilihan tugas pengaturan diri!". Hasil rekapitulasi angket respon ditunjukkan pada Tabel 3.

Sebanyak $32,26 \%$ peserta didik menyatakan bahwa penilaian diri dalam aktivitas penilaian diri yang telah dilakukan membantu untuk mengidentifikasi kesalahan yang dilakukan pada jawaban tes kemampuan kognitif, kemudian dijadikan referensi dalam pemilihan tugas pengaturan diri. Walaupun peserta didik seluruhnya belum secara baik menggunakan hasil penilaian dirinya tetapi peserta didik sudah mampu untuk menentukan tugas pengaturan diri yang dapat membantu mereka memperbaiki kualitas pengerjaan tes. Menurut Kostons, Van Gog, \& Paas (2012) dengan memberi peserta didik kesempatan 
Fatimah., Efendi., Liliawati - Keakuratan Pemilihan Tugas ...

untuk mengontrol tugas-tugas Oleh karena itu, tugas pengaturan diri pembelajaran yang mereka kerjakan dapat menjadi komponen yang dapat dapat meningkatkan keterampilan dilihat dan diukur sebagai pembelajaran mandiri mereka, implementasi kemampuan pengaturan sehingga peserta didik telah memiliki diri peserta didik.

kemampuan dalam pengaturan diri.

Tabel 3. Rekapitulasi Respon Peserta Didik Mengenai Pelaksanaan Penilaian Diri Terhadap Pemilihan Tugas Pengaturan Diri

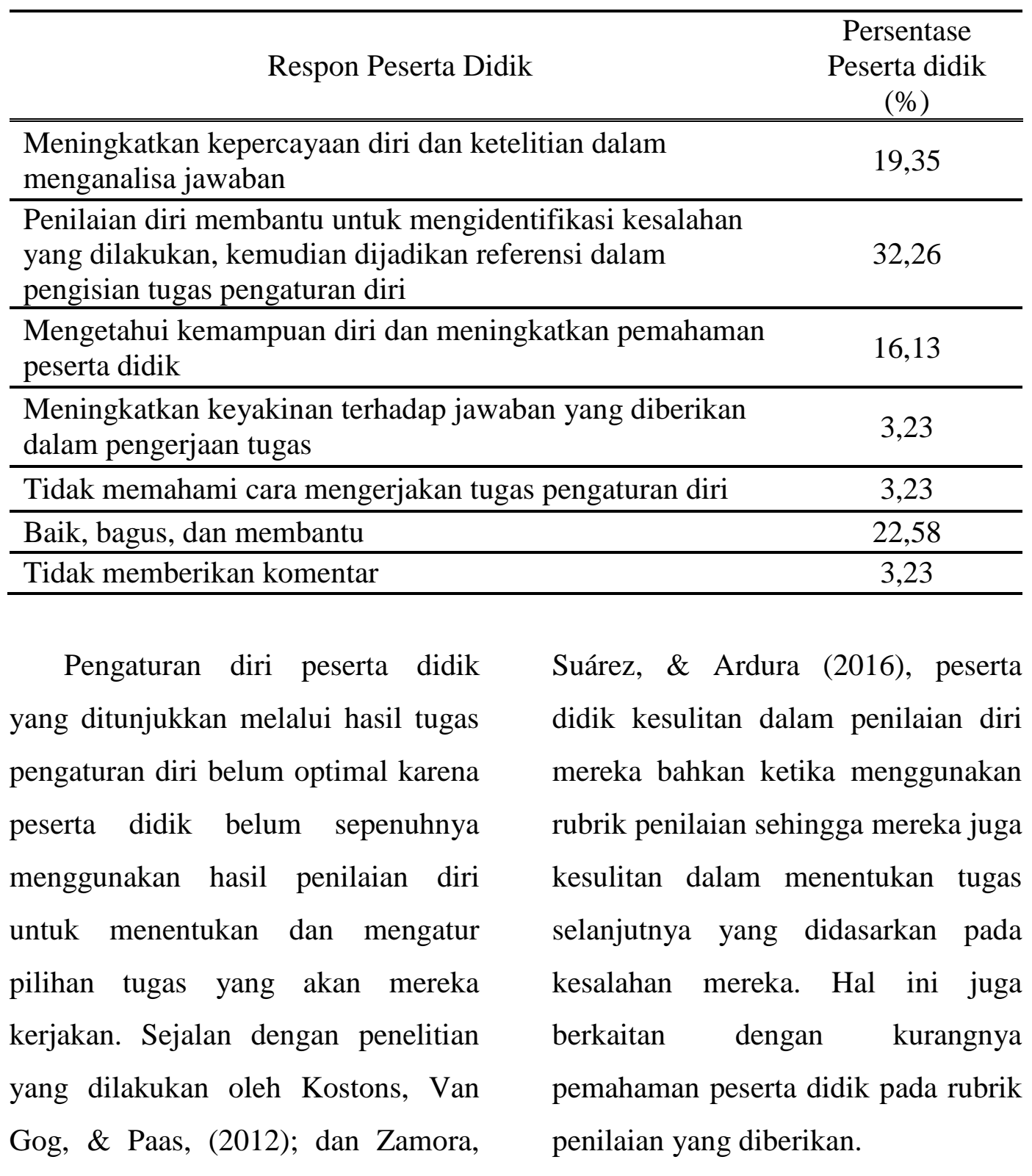


Fatimah., Efendi., Liliawati - Keakuratan Pemilihan Tugas ...

Untuk mengetahui dampak dari pelatihan pengaturan diri yang telah dilakukan terhadap prestasi akademik peserta didik dilakukan uji perbedaan rata-rata pada hasil pre-intervention dan post-intervention test. Data yang diperoleh tidak berdistribusi normal, sehingga uji perbedaan dilakukan menggunakan uji Wilcoxon dengan hasil pengolahan ditunjukkan pada Tabel 4 dan Tabel 5.

Tabel 4. Mean Rank dan Sum of Ranks Pre-intervention dan Postintervention Test

\begin{tabular}{|c|c|c|c|c|}
\hline & & $\mathrm{N}$ & Mean Ranks & Sum of Ranks \\
\hline \multirow{4}{*}{$\begin{array}{l}\text { Skor aktual } \\
\text { pre- } \\
\text { intervention } \\
\text { dan post- } \\
\text { intervention } \\
\text { test }\end{array}$} & $\begin{array}{l}\text { Negative } \\
\text { Ranks }\end{array}$ & $1^{\mathrm{a}}$ & 4,00 & 4,00 \\
\hline & $\begin{array}{l}\text { Positive } \\
\text { Ranks }\end{array}$ & $30^{\mathrm{b}}$ & 16,40 & 492,00 \\
\hline & Ties & $0^{\mathrm{c}}$ & & \\
\hline & Total & 31 & & \\
\hline
\end{tabular}

Tabel 5. Uji Wilcoxon Pre-intervention dan Post-intervention Test Skor aktual pre-intervention dan post-intervention test

\begin{tabular}{lr}
\hline & $\begin{array}{c}\text { Skor aktual pre- } \\
\text { intervention dan post- } \\
\text { intervention test }\end{array}$ \\
\hline $\mathrm{Z}$ & $-4,784^{\mathrm{b}}$ \\
Asymp. Sig. (2-tailed) & 0,000 \\
\hline
\end{tabular}

Tabel 4. menunjukkan bahwa 30 peserta didik mengalami perubahan prestasi akademik yang baik karena hasil post-intervention test lebih besar dari hasil pre-intervention test. Dasar pengambilan keputusan uji Wilcoxon didasarkan pada nilai Asymp. Sig, jika nilai Asymp. Sig $<0,05$ maka terdapat perbedaan antara keduanya. Karena pada hasil uji Wilcoxon pada
Tabel 5. menunjukkan nilai Asymp. Sig sebesar $0,000<0,05$ maka terdapat perbedaan antara rata-rata skor aktual pre-intervention dan postintervention test yang artinya ada perubahan prestasi akademik peserta didik karena pengaruh pengaturan diri peserta didik. Hasil penelitian sejalan dengan penelitian yang dilakukan oleh Zamora, Suárez, \& Ardura 
Fatimah., Efendi., Liliawati - Keakuratan Pemilihan Tugas ...

(2016), bahwa terdapat peningkatan hasil tes kemampuan kognitif terdapat peningkatan pada hasil preintervention dan post-intervention test setelah peserta didik melakukan penilaian diri dan memilih tugas pengaturan diri. Hasil penelitian juga sejalan dengan hasil penelitian yang dilakukan oleh Kostons, Van Gog, \& Paas (2012), bahwa pelatihan penilaian dri dan tugas pengaturan diri dapat meningkatkan kefektifan pembelajaran mandiri sehingga menghasilkan peningkatan signifikan pada kemampuan kognitif dan prestasi akademik peserta didik.

\section{KESIMPULAN DAN SARAN}

Dari hasil penelitian menunjukkan bahwa pengaturan diri peserta didik sudah baik dan berdampak pada prestasi akademik peserta didik. Kinerja peserta didik dalam mengerjakan tugas pengaturan diri berdasarkan kemauan dan kebutuhan mereka tanpa menggunakan hasil penilaian diri sebagai acuannya. Pada hasil angket respon menunjukkan bahwa beberapa peserta didik sudah mampu menggunakan hasil penilaian diri sebaga dasar pemilihan tugas pengaturan diri, dan peserta didik lain memilih tugas pengaturan diri yang dapat membantu untuk memperbaiki kualitas pengerjaan tugas tanpa didasarkan pada hasil penilaian diri. Serta prestasi akademik peserta didik mengalami perubahan yang positif akibat pelatihan pengaturan diri.

Berdasarkan penelitian yang dilakukan agar pengaturan diri peserta didik terlatih dan prestasi akademik menjadi lebih baik maka dibutuhkan pelatihan yang teratur untuk pelaksanaan penilaian diri dan pemilihan tugas pengaturan diri pada kegiatan pembelajaran.

\section{DAFTAR PUSTAKA}

Kostons, D., Van Gog, T. \& Paas, F. (2012). Training SelfAssessment and Task-Selection Skills: A Cognitive Approach to Improving Self-Regulated Learning. Learning and instruction, 22(2), 121-132. doi: https://doi.org/10.1016/j.learnins truc.2011.08.004

Lin-Siegler, X., Shaenfield, D. \& Elder, A. D. (2015). Contrasting Case Instruction Can Improve Self-Assessment of Writing. Educational Technology Research and Development, 63(4), 517-537. doi: https://doi.org/10.1007/s11423015-9390-9

Nugteren, M. L., dkk. (2018). Self- 
Fatimah., Efendi., Liliawati - Keakuratan Pemilihan Tugas ...

regulation of secondary school students: self-assessments are inaccurate and insufficiently used for learning-task selection. Instructional Science, 46(3), 357-381. doi: https://doi.org/10.1007/s11251018-9448-2

Panadero, E., Tapia, J. A. \& Huertas, J. A. (2012). Rubrics and SelfAssessment Scripts Effects on Self-Regulation, Learning and Self-Efficacy in Secondary Education. Learning and individual differences, 22(6), 806-813. doi: https://doi.org/10.1016/j.lindif.2 $\underline{012.04 .007}$

Panadero, E., Jonsson, A. \& Botella, J. (2017). Effects of Selfassessment on Self-Regulated Learning and Self-Efficacy: Four Meta-Analyses. Educational Research Review, 22, 74-98. doi: https://doi.org/10.1016/j.edurev. 2017.08.004

Sari, D. P. (2014). Mengembangkan Kemampuan Self Regulation: Ranah Kognitif, Motivasi dan Metakognisi. Delta-Pi: Jurnal Matematika dan Pendidikan Matematika, 3(2). doi: http://dx.doi.org/10.33387/dpi.v3 i2.135

Supriyanto, S. (2017). Hubungan Antara Self Regulated Learning dan Prestasi Akademik Pada Mahasiswa Semester Pertama Prodi Psikologi Universitas Pembangunan Jaya. Widyakala: Journal of Pembangunan Jaya University, 2(1), 49-61. doi: https://doi.org/10.36262/widyaka la.v2i1.10

Tapia, J. A. \& Panadero, E. (2010). Effects of Self-Assessment
Scripts on Self-Regulation and Learning. Infancia $y$ Aprendizaje, 33(3), 385-397. doi:

https://doi.org/10.1174/0210370 $\underline{10792215145}$

Zamora, Á., Suárez, J. M. \& Ardura, D. (2016). Error Detection and Self-Assessment as Mechanisms to Promote Self-Regulation of Learning Among Secondary Education Students. The Journal of Educational Research, 111(2), 175-185.

doi:https://doi.org/10.1080/0022 0671.2016.122565

Zimmerman, B. (2001). Theories of self regulated learning and academic achievement: An overview and analysis. In B. Zimmerman, \& D. Schunk (Eds.), Self-regulated learning and academic achievement: Theoretical perspectives (pp. 137). Mahwah, NJ: Lawrence Erlbaum.

Zhou, M. (2013). Using traces to investigate self-regulatory activities: A study of selfregulation and achievement goal profiles in the context of web search for academic tasks. Journal of Cognitive Education and Psychology, 12(3), 287-305. doi:

https://doi.org/10.18891/1945$\underline{\text { 8959.12.3.287 }}$ 